\title{
Acquired supravalvar membranous stenosis of the left atrioventricular valve
}

\author{
R P MARTIN, S A QURESHI, * R RADLEY-SMITH \\ From the Department of Paediatric Cardiology, Harefield Hospital, Harefield, Middlesex
}

SUMMARY Acquired supravalvar membranous stenosis of the left atrioventricular valve developed in a nine year old boy with atrioventricular discordance. The supravalvar membrane had not been present when a partial annuloplasty was performed on the left atrioventricular valve eight years before. The stenosis was relieved by operative excision of the membrane.

Membranous supravalvar mitral stenosis is a well recognised condition of unknown aetiology. Shone et al described its association with additional obstructive lesions of the left side of the heart such as parachute mitral valve, subaortic stenosis, and coarctation of the aorta. ${ }^{1}$ It may occur, however, as an isolated lesion ${ }^{23}$ and also in association with the left atrioventricular valve in atrioventricular discordance with ventriculoarterial discordance 4 ("congenitally corrected transposition of the great arteries").

We describe a child with atrioventricular discordance who presented with acquired supravalvar membranous stenosis of the left atrioventricular valve eight years after a partial annuloplasty of the valve ring. Acquired supravalvar stenosis of a prosthetic valve has been described only once before ${ }^{5}$ and this present case is the first in which stenosis of the native valve was caused by a thin membrane that was macroscopically similar to the typical membrane of supravalvar mitral stenosis.

\section{Case report}

A nine year old boy presented with a four week history of intermittent pyrexia and malaise. On examination he had clinical evidence of stenosis of the left atrioventricular valve and of pulmonary hypertension. There was a prominent parasternal impulse

^Present address: Department of Paediatric Cardiology, Royal Liverpool Children's Hospital, Myrtle Street, Liverpool.

Requests for reprints to Dr R P Martin, Department of Paediatric Cardiology, Harefield Hospital, Harefield, Middlesex UB9 6JH. with a long, grade $3 / 6$ apical diastolic murmur and a grade $2 / 6$ apical pansystolic murmur consistent with stenosis of the left atrioventricular valve and mild regurgitation. The pulmonary component of the second sound was accentuated. The respiratory rate was 22 breaths per minute with mild intercostal recession and fine basal inspiratory crepitations.

He was known to have atrioventricular discordance with ventriculoarterial discordance, having presented at three months of age with coarctation of the aorta. Coarctation was repaired by subclavian flap aortoplasty. When he was nine months old a partial annuloplasty was performed on the septal aspect of the left atrioventricular valve because of heart failure caused by atrioventricular valve incompetence. At operation Ebstein's malformation of the left atrioventricular valve was discovered with partial fusion of the septal leaflet and its chordae to the interventricular septum. During follow up there were signs of mild residual valve incompetence and a quiet mid-diastolic murmur thought to represent mild valve stenosis secondary to reduction in the diameter of the valve ring by the annuloplasty.

After the latest admission he continued to have a swinging fever, and bacterial endocarditis was suspected. The electrocardiogram showed complete heart block with a narrow complex escape rhythm at a rate of 70 beats per minute and left atrial hypertrophy. Chest $x$ ray showed cardiomegaly with a cardiothoracic ratio of 0.62 . There was pulmonary venous distension with diffuse parenchymal lung mottling and interstitial pulmonary oedema.

A cross sectional echocardiogram demonstrated atrioventricular discordance and ventriculoarterial discordance. The left atrium was hugely dilated and there was a normal sized, well functioning systemic 
ventricle. The left atrioventricular valve appeared thickened with a restricted opening. A supravalve membrane was not suspected; however, later examination of diastolic frames showed a membrane that was separate from the valve (figure). A Doppler ultrasound estimate of flow velocity across the valve showed a peak "e" velocity of $200 \mathrm{~cm} / \mathrm{s}$ and an end diastolic velocity of $170 \mathrm{~cm} / \mathrm{s}$, giving an estimated transvalvar end diastolic gradient of $12 \mathrm{~mm} \mathrm{Hg}$. In addition there was mild left atrioventricular valve regurgitation. Catheterisation of the right heart showed a pulmonary artery pressure of $120 / 50$ $\mathrm{mm} \mathrm{Hg}$ with a mean pressure of $80 \mathrm{~mm} \mathrm{Hg}$. The mean pulmonary artery wedge pressure was 20 $\mathrm{mm} \mathrm{Hg}$. The left heart was not catheterised because bacterial endocarditis was suspected. A pulmonary arteriogram and follow through showed a dilated left atrium with a stenosed immobile left atrioventricular valve.

Extensive investigations did not find a cause for the pyrexial illness. His cardiac failure became worse, with increasing renal impairment, and so replacement of the left atrioventricular valve was recommended. At operation a thin membrane was found that originated from the atrial aspect of the left atrioventricular valve and was closely apposed to the valve cusps. The membrane was attached to the left atrium near the site of the previous partial annuloplasty and was circular with a small central orifice. The macroscopic appearance was identical to that of "typical" membranous supravalvar mitral stenosis. The membrane was excised and the valve ring was mobilised. Afterwards the valve appeared to be competent with a satisfactory valve orifice diameter. Left atrial pressure after repair was 12 $\mathrm{mm} \mathrm{Hg}$ with a systemic pressure of $85 / 65 \mathrm{~mm} \mathrm{Hg}$

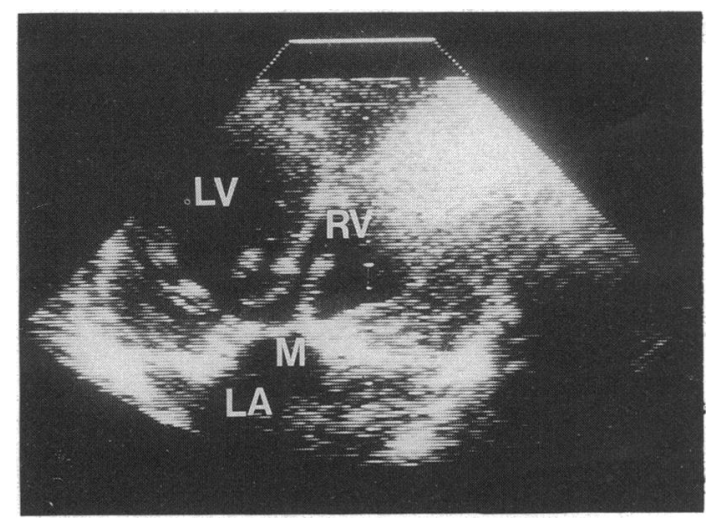

Figure Modified apical cross sectional echocardiogram (diastolic frame) showing the supravalvar membrane (M) closely apposed to the left atrioventricular valve. $L A$, left atrium; $R V$, right ventricle; $L V$, left ventricle. and a pulmonary artery pressure of $60 / 35 \mathrm{~mm} \mathrm{Hg}$.

Postoperative echocardiographic assessment showed a mobile left atrioventricular valve with Ebstein's malformation as previously noted. Doppler assessment showed successful relief of the stenosis with a peak "e" velocity of $180 \mathrm{~cm} / \mathrm{s}$ and no evidence of an end diastolic gradient. There was mild valve regurgitation.

Four weeks after operation the swinging pyrexia recurred and chest $x$ ray examination showed an increase in the diffuse pulmonary shadowing that had been attributed to pulmonary venous hypertension before operation. Open lung biopsy showed severe pulmonary vascular hypertensive disease with features that indicated a superimposed arteritic process. Treatment with steroids was started and he has remained well and apyrexial during six months of follow up.

\section{Discussion}

Supravalvar membranous stenosis of the mitral valve is a potentially curable condition that even with very careful echocardiographic assessment may be difficult to differentiate preoperatively from mitral valve stenosis. ${ }^{6}$ If mitral valve stenosis is erroneously suspected, surgical correction of supravalvar stenosis in younger children may be delayed because valve replacement is usually deferred until an adequate sized prosthetic valve can be inserted. In our patient supravalvar stenosis was not considered because the membrane was not present when valve annuloplasty was performed eight years before.

The aetiology of the membrane is uncertain. It is possible that it resulted from an inflammatory reaction to the suture material used for the previous annuloplasty; however, suture material was only present on the septal aspect of the valve and the membrane was circular with a central orifice. Alternatively, it is possible that the annuloplasty resulted in a fold of redundant tissue in the left atrium that progressively encroached upon the valve because of the mechanical forces exerted upon it by the slightly narrowed valve orifice. The isolated occurrence of supravalvar membranous stenosis of the mitral valve, however, indicates that this cannot be the explanation in all cases. It is unlikely that there is a direct link between the pyrexial illness and the development of the supravalvar membrane because there were signs of important stenosis of the left atrioventricular valve for several years before the development of the pyrexial illness that was attributed to a vasculitis.

Acquired supravalvar mitral stenosis has been described once previously. The obstruction was 
caused by a dense fibrous tissue reaction at the insertion site of a prosthetic valve. ${ }^{5}$ The obstructing tissue had a different macroscopic appearance from the membrane described in our case in which the membrane was thin and pliable.

This case illustrates the difficulty of diagnosing this rare condition before operation and raises questions about the aetiology of supravalvar membranes. If operation has been performed on the atrioventricular valve the possibility of an acquired supravalvar membrane should be considered when signs of atrioventricular valve stenosis subsequently appear.

We are grateful to Professor M H Yacoub for his assistance and advice about this patient.

\section{References}

1 Shone JD, Sellers RD, Anderson RC, Adams P, Lillehei CW, Edwards JE. The developmental complex of "parachute mitral valve", supravalvar ring of left atrium, subaortic stenosis, and coarctation of aorta. Am J Cardiol 1963;11:714-25.

2 Chung KJ, Manning JA, Lipchik EO, Gramiak R, Mahoney EB. Isolated supravalvar stenosing ring of left atrium: diagnosis before operation and successful surgical treatment. Chest 1974;64:25-8.

3 Otero Coto L, Martin Judez V, Juffe A, et al. Supravalvular stenotic mitral ring. A new case with surgical correction. J Thorac Cardiovasc Surg 1976;71:537-9.

4 Chesler E, Beck W, Barnard CN, Schrire V. Supravalvar stenosing ring of the left atrium associated with corrected transposition of the great vessels. $\mathrm{Am}$ J Cardiol 1973;31:84-8.

5 Rogers AK, Morgan JR, Forker AD, Fosburg RG. Supravalvular stenosis after disc mitral valve replacement. J Thorac Cardiovasc Surg 1971;62:810-2.

6 Sullivan ID, Robinson PJ, de Leval MR, Graham TP. Membranous supravalvar mitral stenosis: a treatable form of congenital heart disease. J Am Coll Cardiol 1986;8:159-64.

\section{Notices}

\section{British Cardiac Society}

The Autumn Meeting will be held at the Wembley Conference Centre, London, on 24 to 26 November 1987, and the closing date for receipt of abstracts was 10 July 1987.

The Annual General Meeting for 1988 will take place in Belfast on 23 and 24 March 1988, and the closing date for receipt of abstracts will be 4 January 1988.

\section{Pierre Rijlant prize}

Applications are invited for the Pierre Rijlant prize for cardiac electrophysiology for 1985-7. Information from Professor A Verniory, Académie Royale de Médecine, Rue Ducale 1, B-1000 Brussels, Belgium. 